\title{
COMUNICACIÓN Y TELEVISIÓN EN LA PERCEPCIÓN DE LOS LIDERAZGOS EN PANDEMIA: ANÁLLISIS DE LA GESTIÓN DDE LA CREDIBILIDAD MEDIÁTICA
}

\section{Lola Bañón Castellón}

Universitat de València ${ }^{1}$

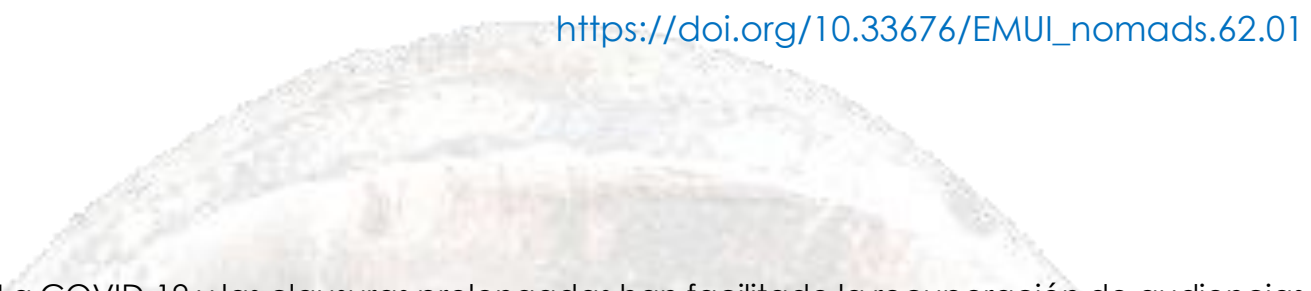

Resumen. - La COVID-19 y las clausuras prolongadas han facilitado la recuperación de audiencias de televisión de forma exponencial después de una larga época de caídas y han consolidado también tendencias informativas previas: la ciudadanía ha simultaneado medios tradicionales con la participación en redes sociales con sus teléfonos, viviendo la alarma a través de informaciones verídicas a veces y de bulos con apariencia formal en otras, en una situación que ha puesto en jaque la credibilidad de muchos medios. En medio de ese torrente de datos, la información emitida por la institucionalidad ha sido fundamental para pedir la implicación de la población. En esta misión ha habido historias de éxito y de fracasos configurados en buena forma por la naturaleza de los comunicadores principales de las instituciones públicas, los gobiernos y las entidades supranacionales. Se trata de la primera pandemia de la historia con intervención de la digitalidad global. Esta circunstancia ha ayudado a las personas a estar en contacto y hacer soportable la situación de confinamiento pero también ha abierto vías de difusión de la información que ha facilitado este material a irresponsables poniendo en peligro la vida humana y cuestionando las fuentes científicas. De esta forma, la propia OMS ha denunciado que no solo el virus sino también la desinformación ha costado vidas humanas y que las estrategias comunicativas pueden ser utilizadas para implicar a las diferentes fuerzas interactivas en una actuación conjunta rápida para atajar las pandemias y las situaciones colectivas de crisis que se generan.

Este artículo contrasta los diversos tipos de liderazgos comunicativos exhibidos por diferentes dirigentes y concluye con una lista de recomendaciones directivas para construir mensajes eficaces en una pandemia que ha mostrado la trascendencia que tienen la comunicación en la constitución de los liderazgos generadores de confianza en situaciones críticas.

\section{Keywords:}

Palabras clave: televisión, liderazgo, COVID-19, pandemia, comunicación corporativa

Abstract.- COVID-19 and the prolonged closures have facilitated the exponential recovery of television audiences after a long period of declines and have also consolidated previous information trends: citizens have combined traditional media with participation in social networks with their phones, living the alarm through true information at times and hoaxes with a formal appearance at others, in a situation that has put the credibility of many media in check. In the middle of this amount of data, the information issued by the institutions has been fundamental in calling for the involvement of the population. In this mission, there have been successful stories and failures shaped largely by the nature of the lead communicators of public institutions, governments and supranational entities. This is the first pandemic in history with global digital intervention. This circumstance has helped people to keep in contact and make the situation of confinement bearable, but it has also opened up channels for the dissemination of information that has facilitated this material to irresponsible creators and disseminators, endangering human life and

\footnotetext{
${ }^{1}$ Lola Bañon Castellón. Profesora de periodismo televisivo en el Departamento Teoría de los Lenguajes de la Facultad de Filología, Traducción y Comunicación de la Universidad de Valencia. Profesora de comunicación corporativa en la Universitat Oberta de Catalunya
} 
questioning scientific sources. In this way, the WHO itself has denounced that not only the virus but also disinformation has cost human lives and that communication strategies can be used to involve the different interactive forces in rapid joint action to tackle pandemics and the collective crisis situations they generate.

This article contrasts the diversity of communicative leadership exhibited by different leaders and concludes with a list of directive recommendations for constructing effective messages in a pandemic that has shown the importance of communication in building trust-building leadership in critical situations.

\section{Keywords:}

television, leadership, COVID-19, pandemic, corporate communication

La figura del líder o lideresa, con habilidades asertivas y de determinación, ha cobrado importancia en las programaciones televisivas especiales de la cobertura de la COVID-19, emisiones prolongadas con una duración que en los momentos críticos ha excedido la de los formatos tradicionales en la pantalla.

Los liderazgos consistentes surgen habitualmente de situaciones complejas y la pandemia ha situado en la línea de prueba a los equipos de comunicación corporativa de las instituciones públicas en todo el mundo. La complejidad y el entorno cambiante han subrayado la necesidad de nuevos modelos de portavocías en los que la empatía, la comprensión, la claridad y determinación son valores al alza

Los confinamientos colectivos han supuesto un inesperado crecímiento del consumo televisivo de naturaleza informativa después de una larga caída de audiencias acaecida en paralelo con el incremento de la adquisición de ficción de las plataformas televisivas de entretenimiento.

Con el cierre de escuelas y universidades, centros culturales, estadios o gimnasios la pantalla en casa se ha convertido en muchos momentos en el vínculo fundamental con el exterior.

Nuevas informaciones pueden suponer asimismo nuevos problemas y por tanto, retos de gestión añadidos. La tecnología digital y el entorno participativo conviven con la comunicación unilateral; el liderazgo no es imaginable sin la interacción y esto coincide en el tiempo con un ecosistema comunicativo en el que la exclusividad de la versión ya no es patrimonio de los medios tradicionales. Son necesarios conceptos que 
nos permitan pensar de una manera nueva esta situación sobrevenida y actuar con ello, a pesar de las dificultades (Beck, 1998)

Así, la COVID 19 lo que ha hecho es acelerar algunos cambios que se estaban ya gestando en el tejido comunicativo. Paradójicamente el aumento de consumo mediático convive con una transición de los modelos de negocio-aún no capaces de oxigenar suficientemente el sector- y la caída de la publicidad por la pandemia.

En este contexto, la ciudadanía ha acudido a los medios tradicionales y en especial a la televisión, pero móvil en mano, buceando y participando en redes sociales, temiendo la enfermedad y viviendo la alarma a través de informaciones verídicas a veces y de bulos con apariencia formal. Ubicada en un torrente de datos, la información emitida por la institucionalidad ha sido fundamental para transmitir la calma a la población y también para pedir su colaboración. La credibilidad de sus líderes y su capacidad de gestionar la función fática de su lenguaje y visualidad han sido relevantes en un momento tan crítico.

\section{Crisis de credibilidad y reacción: la Organización Mundial de la Salud}

El 11 de marzo de 2020 la Organización Mundial de la Salud reconoció la pandemia. La opacidad de las informaciones y la incertidumbre de las informaciones acerca de la extensión de la enfermedad que llegaban desde China, habían retrasado el anuncio con el ánimo de no incrementar la alarma mundial de manera innecesaria.

Esta institución, con anterioridad, ya había padecido crisis de credibilidad. Dependiente de Naciones Unidas, de la misma forma que muchas instituciones supranacionales, ha tenido problemas para encontrar relevancia mediática hasta que la COVID 19 la ha situado en el foco de la actualidad internacional como entidad considerada como la fuente teóricamente más fiable. La OMS tuvo que emitir diariamente recomendaciones, asesorar a gobiernos e intentar realizar planes de actuación de respuesta a una situación de dimensión mundial.

Frente a este reto profesional, la OMS hubo de enfrentarse a un aluvión de noticias falsas distribuidas por las redes sociales, bulos que han dañado en algunos momentos de forma consistente al equipo directivo.

La organización se vio en la necesidad de reduplicar los recursos para la ordenación interna y asegurar la coherencia de contenidos. La respuesta ante el desafío fue configurar un marco estratégico para integrar sus canales de comunicación, ensanchar sus relaciones con los medios, hacer una apuesta decidida por la presencia en los canales audiovisuales y potenciar la comunicación en línea, todo ello con el objetivo de asentar la credibilidad en un momento tan delicado. 
Elaboraron un plan de comunicación en el que las actividades informadas elaboradas por sus equipos internacionales debían ser accesibles, factibles, creíbles, fiables, pertinentes, a tiempo y fáciles de entender (WHO, 2020a) También intentaron adaptarse a los tiempos intentando llegar a los públicos más jóvenes con un perfil de TikTok, en un momento de ascenso de esta red social de origen chino.

Como entidad de Naciones Unidas, la propia naturaleza de la OMS, condiciona toda su estrategia comunicativa. Sus ruedas de prensa, a diferencia de lo que ocurría antaño, han sido reproducidas por los medios generalistas y, por otra parte, estamos ante una institución que trabaja en un área altamente especializada cuyo principal grupo de destinarios esperan información, recomendaciones y orientaciones para adaptar esas medidas a sus países.

Así, en este periodo de pandemia, la OMS se situó como fuente primaria de información para gobiernos y medios de comunicación y su perspectiva de actuación contempla primero de todo el servicio que requiere una emergencia sanitaria global. Pero a diferencia de los gobiernos, su discurso, en tanto que institución de Naciones Unidas, ha de ser de naturaleza diplomática, una limitación que condicionaba su relato, especialmente el de su director general, Tedros Adhanom Ghebreyesus.

En su plan de comunicación, de manera clara, sus principales destinatarios conformaban un grupo en el que se encontraban las personas que adoptaban decisiones sobre su salud y la de sus familias; trabajadores sanitarios, instituciones con responsabilidad sobre la salud de la ciudadanía, comunidades que gestionan espacios y actividades, organizaciones internacionales y los propios representantes de la OMS.

De las posibilidades de aprendizaje que pueden encontrarse en la gestión de esta pandemia podrían hablar mucho los equipos directivos de esta institución supranacional, que ya advirtieron hace años no solamente del advenimiento de crisis sanitarias de esta naturaleza sino de la relevancia del manejo de la comunicación para ayudar a la organización de la lucha contra los brotes víricos de carácter global.

En 2004, la experiencia del SARS (Severe Acute Respiratory Syndrome) hizo que los equipos directivos profundizaran en la conciencia de considerar la comunicación como un elemento relevante en el plan de lucha. Reconocieron, primero, que era esencial en el intento de parar los brotes por la necesidad de incidir en la sensibilización sobre las medidas y segundo, que podría ayudar a mitigar el impacto de las pandemias desde el punto de vista social y económico. Los expertos de la organización aventuraban en sus documentos que el cambio climático estaba generando mejores condiciones para la supervivencia y expansión de los virus. 
La Organización Mundial de la Salud, en aquel momento en que aún las redes sociales no tenían la expansión de hoy en día, ya pactaron pautas profesionales de relación con los medios admitiendo que las estrategias comunicativas pueden ser utilizadas para implicar a las diferentes fuerzas interactivas en una actuación conjunta rápida para atajar las pandemias.

La organización reconoce la importancia de contar con un liderazgo eficiente en los gobiernos de los países para resolver la situación; la fortaleza de la dirección es un factor positivo para que las poblaciones puedan diluir sus dudas e inseguridades cuando los brotes aparecen e incluso la respuesta políica a la situación de infección puede estimular la reacción ciúdadana y la solidaridad, elementos fundamentales para solucionar la crisis. La OMS pone a Hong Kong en la crisis del SARS como ejemplo de eficacia comunicativa: las autoridades reconocieron la importancia de estar disponibles ante los medios y esta estrategia contribuyó a disminuir la ansiedad que mostraba la población. Esta comprensión ayudó a sensibilizar a la ciudadanía que, de esta forma, metabolizó esa sensación negativa en deseo de implicación y colaboración para ayudar al esfuerzo colectivo (WHO,2005)

El 11 de marzo, día de la declaración de la pandemia, Tedros Adhanom Ghebreyesus denunció sin especificar nombres, la inacción de algunos países. Ello se debe a que la OMS no es una organización poderosa, no tiene poder sancionador y cuenta con un magro presupuesto de dos billones de dólares. No tiene condiciones para liderar una respuesta internacional a una pandemia como la que padecemos. Le han ido quitando poder y recursos (Buranyi,2000)

Una organización como la OMS necesita tener aliados y no enemigos, esa es la convicción personal de su director para establecer un liderazgo con intenciones colaborativas. Por ello practicó una política de neutralidad estética, sin mostrar critica a China, convencido como estaba de que no había que cortar interlocuciones a pesar de que el país rehusaba aceptar inspectores de la organización y no actuaba con transparencia. El retraso en reconocer la pandemia ha sido admitido posteriormente como una equivocación estratégica y una quiebra en la credibilidad de la institución. Una petición en línea reunió un millón de firmas solicitando la dimisión de Tedros Adhanom Ghebreyesus.

No obstante, la COVID-19 ha mostrado la necesidad de una institución supranacional como la OMS. Frente a la actitud de la administración Trump y su recorte de fondos, la Unión Europea en cambio, ha reiterado su apoyo, pidiendo incluso a los Estados Unidos la reconsideración de su postura; algo que se confía ocurra durante el mandato Biden. 
Para muchos expertos, la entidad sufre la peor crisis desde 1948, cuando fue fundada. Y eso ocurre en un momento crítico en la historia de la humanidad.

\section{Fake news e infodemia}

La OMS, en esta pandemia, se enfrentó a la situación de tener que cumplir su cometido por un parte y de además vere obligada a abrir acción en un nuevo frente, el de defender su reputación en las redes sociales en donde las noticias falsas volaban incluso con logos falseados que pretendía simular ser de la organización causando miedos y angustia en la población. Los responsables de comunicación le pusieron a esta nueva lacra el nombre de infodemia, una sobreabundancia informativa que incluye intentos deliberados de diseminar informaciones falsas para minar la respuesta sanitaria global y promover agendas alternativas provenientes de individuales (WHO,2020b)

Antes de declarar la pandemia, la OMS decretó en enero de 2020 la emergencia de salud pública internacional. Con anterioridad, esta alerta solo ha sido declarada en cinco ocasiones: en 2009 con la gripe HIN1, en 2014 y 2019 con los brotes de Ébola en África, en 2014 por la polio y en 2016 por el virus Zika.

La COVID-19 es una pandemia en la que la digitalidad interviene de forma global. Esta circunstancia ha ayudado a las personas a estar en contacto y hacer soportable la situación de confinamiento pero también ha horadado vías de difusión de la información que ha facilitado este material preciado a manos irresponsables poniendo en peligro la vida humana y cuestionando las fuentes provenientes de la ciencia. De esta forma, la propia OMS ha denunciado que no solo el virus sino también la desinformación ha costado vidas humanas.

Por ello, en abril del 2020, días después de declarada la pandemia, el Secretario Nacional de Naciones Unidas, Antonio Guterres lanzó una iniciativa oficial para combatir la desinformación. Al mes siguiente, en la Asamblea General de la Organización Mundial de la Salud se aprobó la resolución WHA73.1 para la respuesta a la COVID-19, ún texto que reconoce que la gestión de la infodemia es parte vital para el control de la pandemia. Insta a los estados miembros a aplicar medidas de prevención para evitar ciberactividades que puedan comprometer la eficacia de la respuesta sanitaria (United Nations,2020)

La OMS, a pesar de este esfuerzo diplomático, ha tenido que soportar graves ataques de la presidencia de Donald Trump, quien les acusó de proteger a China en los inicios de la extensión del virus. Una situación que sobrellevó con templaza su director, Tedros Adhanon, sometido diariamente a comparecencias públicas en ruedas de prensa interminables. Siempre aparecía rodeado de expertos requeridos por la 
organización para dar respuesta convincente a los medios que preguntaban cuestiones técnicas en directo.

Las noticias falsas en nombre de la OMS han llegado a producir momentos de diferencias en el seno de la organización. Y los problemas comunicativos siempre tienen una incidencia no solo en la credibilidad sino además en las cohesiones internas de las estructuras. La crisis del coronavirus nos indica la necesidad de reflexionar sobre los cambios que han de integrar las instituciones supranacionales para gestionar la desinformación de forma eficiente y rápida. La velocidad que marca el mundo de la digitalidad no permite las operaciones de contraste y verificación con los tiempos tradicionales.

En esta lucha contra las fake news ${ }^{2}$, la OMS, recursos para ampliar las posibilidades de obtener información directa de la organización. Uno de ellos ha sido el chatbot, el programa informático que permite mantener conversaciones virtuales, disponible en seis idiomas (Crosas,2020)

Esta herramienta ha sido especialmente útil para los periodistas que hemos cubierto la pandemia para medios audiovisuales públicos, puesto que diariamente era posible acceder a un mapa oficial de la organización en el que con un solo click era instantáneo el obtener las cifras de infectados y victimas mortales, actualizadas al momento.

También el gobierno español puso en marcha en el mes de abril el llamado Hispabot Covid-19, un canal de consulta a través de WhatsApp, fruto de la inteligencia artificial, que permite la resolución de cuestiones básicas sobre la enfermedad con información oficial.

Institucionalidad y expectativas comunicativas de la sociedad civil en tiempos de pandemia

En tiempos de pandemia, la comunicación ha debido adaptarse rápidamente. Es un momento en que se espera que las administraciones asuman un papel fundamental en la reactivación de la economía a la vez que organicen la seguridad sanitaria de la ciudadanía (Pellicer,2020)

Tras el reconocimiento de la dificultad del objetivo, hay que entender que una pandemia sobrevenida de forma inesperada y con una expansión acelerada genera un estado de angustia en la ciudadanía. Y esta es una situación que ha de ser asumida por el sistema de las instituciones. De ahí la necesidad, no sólo de actuar (algo que incluye el reconocimiento de que en todo plan de este tipo siempre se pueden producir errores y que nadie tiene la fórmula del éxito asegurado de forma anticipada) sino además de estructurar una comunicación capaz no solo de contar lo que se hace, sino de transmitir valores y la percepción de que los ciudadanos

\footnotetext{
2 Noticias falsas
} 
y ciudadanas están en manos responsables. Es fundamental evitar la generación de incertidumbre.

En países como España, las apariciones de los representantes políticos fueron diarias tanto los pertenecientes al gobierno central como el de las autonomías.

En este sentido, la situación de restricción de la presencialidad dió por primera vez amplitud a una situación ocurrida con anterioridad solo de forma excepcional: las ruedas de prensa on line emitidas en directo también por las televisiones, en donde los periodistas efectuaban las preguntas, conectados desde sus casas. Este sistema ha permitido la conexión simultánea de centenares de periodistas, algo que ha obligado a los equipos de comunicación a gestionar ordenes de intervención y a implementar filtrados de preguntas que han derivado en críticas en diferentes medios y en un manifiesto firmado por quinientos periodistas titulado "La libertad de preguntar".

Siendo como es una práctica habitual la ordenación de turnos en este tipo de eventos, es de vital importancia no quebrantar el derecho constitucional a comunicar y a recibir información veraz. Establecer un orden no significa filtrado de preguntas.

Justamente en Italia, uno de los éxitos comunicativos de su primer ministro, ha sido el aceptar cuestiones en un momento de crisis máxima para un país que ha encabezado la lista de víctimas europeas desde el momento cero. Giuseppe Conte, un abogado que antes de asumir la presidencia tenía una relativa experiencia política, ha construido su credibilidad en este aciago y delicado periodo trabajando su contacto diario a través de la televisión y con un comedido pero certero uso de las redes sociales. Conte estuvo aconsejado por un equipo de profesionales que en un periodo tan complicado como fue el de emergencia inicial le ayudó a mostrarse como un líder empático, solvente, sereno ante la toma de decisiones y dispuesto a proteger los intereses italianos. No hay que olvidar que Italia fue señalada en esos primeros momentos como difusora principal de la extensión del virus en Europa. Conte profundizó en el discurso del momento histórico al que hacía frente un país que venía saturado de momentos de protagonismos políticos personalistas con una figura como Matteo Salvini. Un caso similar al de Conte ha sido el del gobernador de Nueva York, Andrew Cuomo, enfrentándose no solo a la crisis sino al populismo y la negación del presidente de los Estados Unidos, Donald Trump.

En esta situación de emergencia, la comunicación de los líderes durante el periodo COVID se ha generado en un momento en el que los medios tradicionales han perdido la hegemonía de la palabra en el espacio publicado/televisado. 
La reputación, al contrario que la imagen corporativa, es propiedad del público y supone la representación colectiva de un rendimiento (Wilcox, Cameron y Xifra,2012:278). En estos complicados tiempos ha sido un valor extremadamente complicado de mantener y un desafío para los liderazgos políticos. Hablamos de un concepto abstracto, que depende de los receptores y es de difícil medición (Aced,2018:32)

Los dirigentes han tenido la oportunidad a través de las redes sociales de establecer contacto directo e instantáneo con la ciudadanía, especialmente a través de la plataforma Twitter. Ello les ha permitido dirigirse al público con otro tipo de lenguaje, menos institucional, más afectivo e incluso épico, con frecuentes referencias a la familia, al espíritu de sacrificio conjunto y a la necesidad de protección de los más débiles; valores bien inscritos en la personalidad colectiva mediterránea que contiene evidentes actitudes reconocidas también por la cultura religiosa. Estamos en el momento de la llamada diplomacia 2.0, que se define como una herramienta utilizada por la diplomacia pública para influenciar al público a través de las redes (Vera,2018)

La digitalidad, de esta forma, al generar espacios de conversación entre los usuarios y usuarias produce contenidos opuestos: crea grupos de oposición incluso violenta, aunque también colectivos de fidelidad de personas capaces de dar apoyos en situaciones de vulnerabilidad como la del COVID, incluso con consistencia mayor a la presentada por los críticos.

La forma de gestionar estos momentos en una comunicación de crisis permite la determinación de modelos tal y como ha conformado un estudio italiano que distingue hasta cinco estilos diferentes de discursos en los líderes europeos.

Angela Merkel, la canciller alemana, única mujer entre los dirigentes escogidos, es calificada como la madre de los alemanes. Calma y responsabilidad con la recomendación del cuidado personal y de la atención a los nuestros han sido los ingredientes de sus intervenciones. Tras sus alocuciones al país ha llegado a conseguir el 80 por ciento del apoyo de sus compatriotas, lo que supone hoy en día casi el porcentaje correspondiente a una aclamación.

Emmanuel Macron, el presidente francés, en cambio, se dirigió a su pueblo calificando textualmente la situación de guerra y diseñando el escenario como si de una operación militar se tratase, finalizando con un patriótico "Vive la France".

El primer ministro británico, Boris Johnson, por su parte ha sido quien ha efectuado las operaciones estratégicas más erráticas, pues pocas cosas hay más peligrosas en comunicación que la obligación de corregir el rumbo por quedar al aire la incoherencia. 
El premier inició la crisis advirtiendo que la gente se preparara incluso para perder a seres queridos y proclamando que la gran ventaja de no imponer medidas severas seria conseguir la llamada inmunidad de rebaño.

Le ayudó a remontar su imagen el hecho de haber sido él mismo un contagiado al borde de la muerte y salir de la experiencia con un discurso optimista y profusión de presencia pública.

De Conte, el entonces primer ministro italiano, se señala además destaca la apelación a la solidaridad europea con su "nessuno si salva da solo"3

El estudio italiano finalmente destaca los mensajes de Sánchez, textualmente, como los más dramáticos, reconociendo que se enfrenta a un problema que los otros líderes no tienen: una diversidad territorial y un fraccionamiento ideológico que le llevó a hacer constantes referencias a la necesidad de unidad y a que los ciudadanos y ciudadanas estaban por encima de las ideologías, motivo que el resto de mandatarios europeos no incluyó en sus discursos (Brunelli y Mollinari,2020)

Género y nuevos liderazgos: el ejemplo de Jacinta Ardern

Frente a estos cinco líderes europeos que obtienen valoración desigual, el caso de la primera ministra neozelandesa es un ejemplo paradigmático de la trascendencia imprescindible que tiene la comunicación en la constitución de los liderazgos.

Jacinta Ardern anunció las medidas de restricción el 21 de marzo en una intervención televisada de ocho minutos en la que pidió abiertamente la colaboración de la ciudadanía y en la que se sometió a las preguntas de los informadores.

La política de apertura a las cuestiones de la prensa, que siempre es un punto positivo en la comunicación corporativa de las instituciones es la que siguieron, hay que decirlo, buena parte de los gobiernos de la Unión Europea

Pero Ardern no solo tuvo la ventaja circunstancial de la insularidad de Nueva Zelanda en el control del virus, sino que además supo ponderar la grave situación que vivían ya Italia y España y no por estar en las antípodas minimizó el riesgo. Su primer gran acierto fue la rápida reacción como prueba que el 80 por ciento de los neozelandeses mostrasen apoyo a su gestión. Este es, por lo ocurrido también con Merkel, el nivel de aceptación masiva de las líderesas femeninas. Cumplió con el gran mandamiento de la efectividad comunicativa que es la acción en la anticipación.

Su discurso fue claro y lleno de agradecimientos por los sacrificios de la población. Pocos reparan en que Ardern acudió a esta cita del destino ya con la autoridad que le confirió el liderazgo que mostró en la gestión del

\footnotetext{
${ }^{3}$ Traducción: "Nadie se salva solo"
} 
atroz atentado a dos mezquitas de Christchurch cometido por un supremacista, meses antes. Su actitud firme en la condena en paralelo a la compasión mostrada por las familias de las 51 víctimas la elevó a la más alta consideración en el ranking de los líderes mundiales más apreciados.

No estamos hablando de impresiones o sensaciones sino de conductas en el ámbito público estudiadas y ponderadas, entre las que destaca por ejemplo el modelo de los Mayfield, que señala tres características clave en el comportamiento de los lideres: capacidad directiva, habilidad para dotar de significado y empatía. El estudio de los citados autores defiende que la primera virtud se suele sobrevalorar mientras que las otras dos, muchas veces, no son apreciadas de forma relevante. La respuesta de Ardern, no obstante, contiene de forma clara los tres enfoques (Wilson, 2020)

En definitiva, la identificación es un elemento fundamental y esta se nutre en buena parte a través de los lenguajes motivadores de los lideres, en un proceso que contempla el conocimiento de los seguidores y su inclusión en el contexto cultural (Mayfield, Mayfield y Walker,2020)

Conclusiones para una aplicación práctica en los liderazgos en crisis

Tras una prolongada batalla aún inconclusa contra la pandemia, podemos extraer una lista de recomendaciones comunicativas en la construcción de liderazgos conectados con la realidad de la situación:

1-No retrasar la respuesta. Es necesario detectar cuando el público tiene una necesidad de reacción, máxime en una cuestión de salud e incluso de riesgo vital como ha sido la crisis del coronavirus. La intención de no alarmar ha coincidido en este caso con muchos líderes públicos con el deseo de transmitir que las cosas van bien y que eso es así porque están gestionadas. Se trata de una combinación muy peligrosa desde el punto de vista de la comunicación corporativa; porque cuando las cosas empeoran el tiempo se encarga de hacer fosfatina la llamada a la calma del líder. Y si este o esta dirigente no ha dicho la verdad inicia su camino a la oscuridad.

2-Claridad y sinceridad en la comunicación. No hay que emitir discursos paternalistas; un líder no es un enviado de Dios; es una persona que expone claramente la parte de trabajo que cada uno ha de realizar, que explica que es necesario que cada una de las personas ponga de su parte para que no caiga el sistema. Este discurso además fortalece la cohesión grupal de las sociedades, mejora la identificación de grupo y facilita la creación de la identidad colectiva, algo fundamental cuando se afronta una situación como la pandemia. El lenguaje ha de ser accesible, pero correcto. Hay que abatir ese prejuicio tan extendido entre parte de la academia de que hay que banalizar el nivel de la expresión para que el pueblo la entienda. La ciudadanía ha de trabajar profusamente para ganarse la vida y muchos no tienen títulos ni certificados, pero son 
diplomados y diplomadas en sabiduría vital y sobre todo, sienten desconfianza con quienes no hablan de forma transparente.

3-Armonizar la responsabilidad con la esperanza. Si el líder llama a la implicación para resolver un problema grave ha de insuflar la suficiente perspectiva épica para visualizar la solución de la crisis. Esto no está vinculado con las promesas falsas, sino con la convicción de que el esfuerzo colectivo es la única vía que nos saca del desastre.

4- No caer en la culpabilización como vía de exención de la responsabilidad propia. El foco debe estar puesto en la meta y el objetivo. El error, si es aceptado y disculpado puede ser gestionado. Si es negado se convierte en una evidencia todavía más visible y en un peso para seguir avanzando.

5- Los líderes y las lideresas deben cuidarse en tiempos de crisis, pero no pueden hacer exhibiciones de descanso, por la sencilla razón de que buena parte de la gente, en su lucha por la supervivencia, no puede permitirse asueto. Y esa actitud de estar siempre al pie del cañón, además de mantenerse ha de comunicarse. El liderazgo en tiempo de crisis exige presencia y además control de la misma. El líder no ha de ser sorprendido en una situación de la que no puede disfrutar su gente.

6-La comunicación está para ayudar a amortiguar las consecuencias económicas de la crisis, pero también para transmitir esperanza y energía. La buena comunicación actúa como un escudo ante los acontecimientos que pueden alterar el funcionamiento normal de una organización. La recuperación tiene un componente racional y otro emocional (Velasco,2000)

7-Distinguir entre sobreexposición y el sostenimiento de la presencia responsable. En contra de lo que siente buena parte de la clase política, en un mundo interconectado en donde hay posibilidades infinitas de difundir datos y posibilidades relativas de encontrar la verdad, el exceso de aparición no solo conduce a la saturación, sino también a la multiplicación de posibilidades de ser preguntado o preguntada por temas que no previstos ante los que no se puede reaccionar. Los líderes han de tomar decisiones y comunicarlas, pero la transmisión y la comunicación es solo parte de un proceso: hay que tomar un tiempo para el trabajo meditativo de la acción. Si la decisión está basada únicamente en razones estéticas o de marcaje del territorio mediático mediante la presencia, en un momento y otro aparecerá la vulnerabilidad. Si una persona es solo un presunto líder y por tanto, únicamente la construcción de un personaje, pronto y en la ocasión más inesperada aparecerá el síndrome del globo deshinchado,

8-Construir la confianza. Este es un elemento basal en el edificio comunicativo. Organizaciones internacionales como la OMS dan en llamar "el triángulo de la confianza" a una situación en la que los técnicos han de entender que han de dar información clara; los comunicadores han de 
asumir que los científicos necesitan la exactitud en los datos y que ellos han de situar la narración en el contexto político y cultural. Finalmente, los gobernantes deben aceptar que la ciudadanía necesita información y que los periodistas, que hacen este trabajo de intermediación requieren respuestas convincentes de estas autoridades.

Finalmente, la pandemia ha evidenciado la necesidad de sistemas públicos sólidos en la sanidad y se ha demostrado asimismo que la información ha sido fundamental en el trabajo de concienciación social para lograr una respuesta de la ciudadanía frente al coronavirus. Ha sido decisiva también en la comunicación de las decisiones políticas que han afectado a la población en un periodo tan delicado como el de los confinamientos.

La crisis asimismo nos da nuevas claves que evidencian la dificultad de regular los comportamientos públicos colectivos. La imposición con fuerza es inservible; el poder hoy es la capacidad de conseguir aceptación y no acatamiento para las propuestas (Gutiérrez,2020) Los nuevos líderes y lideresas que afrontan el nuevo diseño del mundo postpandemia han de comunicar valores. Y en ese discurso han de mostrar coherencia y también una confianza que no es solo cuestión de sentimientos sino de preparación en la gestión y de organización en la comunicación. La comunicación corporativa demuestra una vez más que los discursos no solo contienen contenidos sino además formas de gestionar la cohesión y la organización social.

\section{Bibliografia}

Aced, Cristina (2018) Relaciones Públicas 2.0. Cómo gestionar la comunicación corporativa en el entorno digital. Editorial UOC.Barcelona

Beck, Ulrich (1998) La sociedad del riesgo. Hacia una nueva modernidad. Paidós. Barcelona

Buranyi, Stephen(2020)_The WHO v coronavirus: why it can't handle the pandemmic. The Guardian

The WHO v coronavirus: why it can't handle the pandemic | World Health Organization | The Guardian 
Brunelli, Roberto. y Molinari, Paolo (2020) Coronavirus e comunicazione: cinquestili per i leader europei.AGI Agenzia Italiana https://www.agi.it/estero/news/2020-04-15/coronavirus-comunicazioneleader-8346598/

Crosas, Maria (2020) 5Chatbots that combat fake news on the COVID19 https://dinfografia.wordpress.com/2020/04/1 1/covid19-chatbots-thatgive-you-trustworthy-data/

Gutiérrez Rubí, Antonio (2020) El poder del comportamiento https://www.gutierrez-rubi.es/2020/12/1 1/el-poder-del-comportamiento/ Kerryssey, Micaela.yEdmondson,Amy (2020) What Good Leadership Looks Like During This Pandemic. Harvard Business review https://hbr.org/2020/04/what-good-leadership-looks-like-during-thispandemic

Mayfield,Milton;Mayfield, Jacqueline y Walker,Robyn.(2020) Leader Communication and Followerldentity: How Leader Motivating Language Shapes Organizational Identification through Cultural Knowledge and Fit. International Journal of Business Communication. https://journals.sagepub.com/doi/pdf/10.1177/2329488420979285

OPS, Organización Panamericana de la Salud (2020) Comunicación de riesgos y brotes https://www.paho.org/es/temas/comunicacion-riesgosbrotes

Pellicer, Miquel (2020) El informe de Mary Meeker sobre las tendencias de la pandemia https://miquelpellicer.com/2020/05/informe-mary-meekerpandemia-tecnologia-coronavirus/

Shaw, Richard (2020)2020 hindsight: can New Zealand apply the political lessons of COVID-19 in theyear ahead?

https://theconversation.com/2020-hindsight-can-new-zealand-applythe-political-lessons-of-covid-19-in-the-year-ahead-151830

Velasco, José.Manuel(2020). The nine challenges PR will face after the pandemic

https://www.globalalliancepr.org/thoughts/2020/12/11/the-ninechallenges-pr-will-face-after-the-pandemic

Vera, Evelyn (2018). El futuro de la diplomacia en la era digital. Nexoshttps://www.nexos.com.mx/?p=39947WHO(2005) Out break communication: Best practices for communicating with the public during an outbreak https://www.who.int/publications/i/item/outbreakcommunication-best-practices-for-communicating-with-the-publicduring-an-outbreak

WHO (2020a) Strategic Communications Framework https://www.who.int/about/what-we-do/strategic-communicationsframework/es/ 
WHO (2020b) Join tstatement by WHO, UN, UNICEF, UNDP, UNESCO, UNAIDS, ITU, UN Global Pulse, and IFRChttps://www.who.int/news/item/2309-2020-managing-the-covid-19-infodemic-promoting-healthybehaviours-and-mitigating-the-harm-from-misinformation-anddisinformation

United Nations (2020) United Nations Guidance Note on Addressing and Countering COVID-19 related Hate Speech

https://www.un.org/en/genocideprevention/documents/Guidance\%20 on\%20COVID-19\%20related\%20Hate\%20Speech.pdf

Will,Dennis;Cameron,Glen y Xifra, Jordi.(2012) Relaciones públicas, estrategias y prácticas. Madrid. Pearson

Wilson,Suze.Coronavirus: las tres lecciones de liderazgo de la primera ministra de Nueva Zelanda https://theconversation.com/coronavirus-lastres-lecciones-de-liderazgo-de-la-primera-ministra-de-nueva-zelanda136146 